\title{
PERFIL COMPORTAMENTAL DOS CONTROLLERS NO BRASIL: COMO ESTÃO OS NOSSOS PROFISSIONAIS?
}

Controllers' Behavioral Profile in Brazil: how are our professionals?

Luciane Reginato

E-mail: lucianereginato@usp.br

Doutora em Controladoria e Contabilidade (USP)

Endereço para contato: Av. Prof. Luciano Gualberto, 908, FEA 3, Butantã, São Paulo - SP, 05508-210

https://orcid.org/0000-0003-1812-4311

Samuel de Oliveira Durso

E-mail: sodurso@gmail.com

Doutor em Controladoria e Contabilidade (USP)

Endereço para contato: R. Maestro Cardim, 1170 - Bela Vista, São Paulo - SP, 01323-001

https://orcid.org/0000-0003-0016-3611 


\section{RESUMO}

A área conhecida como Controladoria exerce um importante papel para assegurar a saúde econômico-financeira das entidades. Assim, analisar os fenômenos inerentes aos profissionais da área ajuda a compreender como eles podem auxiliar no desempenho das organizações. Nesse contexto, esta pesquisa buscou identificar o perfil comportamental dos controllers atuantes em empresas no Brasil. Para isso, foi realizado um levantamento, por meio de questionário, obtendo 104 respostas válidas de profissionais da Controladoria. O questionário foi aplicado entre agosto de 2019 a julho de 2020. A análise de dados contou com correlações e regressões lineares múltiplas. As evidências indicam que os atuantes da Controladoria de empresas brasileiras apresentam bons níveis de motivação, poder de tomada de decisão, conscienciosidade e capacidade de trabalhar em equipe. Em contrapartida, foi possível identificar a presença de comportamentos geradores de estresse e necessidades de melhorias nas características interpessoais desses profissionais. Como principais variáveis explicativas do perfil comportamental dos indivíduos da amostra, destacam-se a idade, o tempo de experiência e o estado civil. A pesquisa contribui para um melhor entendimento sobre as características presentes em controllers que atuam em empresas no país, auxiliando na evolução da literatura sobre a atuação dos profissionais da Controladoria. Adicionalmente, a investigação contribui para uma reflexão sobre a formação dos controllers no Brasil, levantando características e habilidades importantes para a atuação desses profissionais. $O$ estudo permite, ainda, impulsionar incentivos para o desenvolvimento pessoal e profissional dos atuantes na Controladoria, os quais apresentam papel central no desempenho econômicofinanceiro das empresas.

Palavras-chave: Perfil Comportamental, Controllers, Controladoria.

\section{ABSTRACT}

The area known as Controllership plays an important role in ensuring the economic and financial health of the entities. Thus, analyzing the phenomena inherent to those working in the area helps to understand how these professionals can assist in the performance of organizations. In this sense, this research aims to analyze the controllers' behavioral profile working in companies in Brazil. For this purpose, we applied questionnaires, obtaining 104 valid responses directly from professionals working in Controllership. To analyze the data, we estimated correlations and multiple linear regressions. The evidence indicates that the controllers of Brazilian companies have good levels of motivation, decision-making power, conscientiousness, and ability to work as a team. On the other hand, it was possible to identify the presence of stress-generating behaviors and the need to improve the interpersonal characteristics of these professionals. The main explanatory variables of the controllers' behavioral profile in the sample are age, time of experience and marital status. The research contributes to a better understanding of the characteristics necessary for acting as a controller, helping in the evolution of the literature on the subject. Additionally, the investigation contributes to a reflection on the training of controllers in Brazil, raising important characteristics and skills for the performance of these professionals. The study also allows to boost incentives for the personal and professional development of those working in the Controllership, which play a central role in the economic and financial performance of companies.

Keywords: Behavioral Profile, Controllers, Controllership. 


\section{INTRODUÇÃO}

A área de Controladoria exerce um papel fundamental para a manutenção da saúde econômico-financeira das organizações. Conforme ponderam Oro et al. (2013), por meio da Controladoria torna-se possível identificar, de uma forma detalhada, problemas organizacionais que impactam no resultado das entidades. Nascida em um contexto multidisciplinar, a Controladoria possui funções relacionadas a diversas frentes como planejamento estratégico, reporte de informações contábeis, controle de ativos e avaliação econômica, por exemplo (Lunkes et al., 2013; Siqueira \& Soltelinho, 2001).

Leite (2013) destacou que o meio no qual a organização está inserida pode influenciar nas práticas utilizadas pela Controladoria. Nesse contexto, a atuação dos controllers torna-se ainda mais importante em cenários de crises ou restrições financeiras, quando o acesso aos recursos escassos da economia exige maior otimização por parte das empresas. A pesquisa de Nunes e Sellitto (2016) destacou a existência de 27 atividades de Controladoria, diversas delas relacionadas com o processo de otimização de recursos, tais como análise da cadeia de valor, processo orçamentário e planejamento tributário.

Mesmo com a crescente importância da área de Controladoria para as empresas, a literatura tem observado diferenças na forma de atuação dos Controllers no mercado (Borinelli, 2006; Leite, 2013; Siqueira \& Soltelinho, 2001). Lunkes et al. (2011) destacaram, inclusive, que a academia também não apresenta um consenso no que diz respeito à atuação da Controladoria nas empresas. Muitas vezes, as atividades da Controladoria aparecem sobrepostas com as da área da contabilidade ou financeira. A pesquisa de Gomes et al. (2014) encontrou evidências de que uma das principais atribuições relacionadas com a Controladoria, o planejamento, não é listada no processo de contratação dos profissionais da área. Já, o estudo de Rengel et al. (2020) comprovou que existe relação direta e positiva entre características dos gestores e a participação orçamentária.

Apesar de a literatura nacional apresentar importantes investigações sobre o perfil demandado pelo mercado brasileiro para os profissionais da área da Controladoria (Gomes et al., 2014; Oro et al., 2009, 2013; Peleias et al. 2008; Siqueira \& Soltelinho, 2001) e as atividades mais comumente realizadas pelos controllers (Leite, 2013; Lunkes et al., 2011, 2013), ainda se mostra importante analisar os diferentes perfis comportamentais dos controllers no mercado mencionado, o que guarda uma relação direta com o desempenho operacional e global das organizações.

Sob a ótica comportamental, cabe destacar a relevância dos traços de personalidade de cada indivíduo, que, também, podem representar fator decisivo para o desempenho da empresa. Essa vertente da psicologia visa a apoiar o desvendar das nuances do comportamento individual a fim de potencializar os traços positivos e minimizar aqueles 
negativos (Gerrig \& Zimbardo, 2002). Nessa linha, entender os traços ou mesmo as características do profissional da área de Controladoria pode contribuir para a execução de suas funções e, consequentemente, para o atendimento de metas e objetivos.

Sendo assim, buscando contribuir para o desenvolvimento da literatura acerca de Controladoria, a questão de pesquisa que orientou o presente estudo foi: qual o perfil comportamental dos controllers de empresas no Brasil? O objetivo geral da pesquisa consistiu, portanto, em identificar o perfil comportamental dos controllers atuantes em empresas no Brasil. Adicionalmente, a pesquisa buscou identificar fatores internos e externos aos indivíduos que pudessem ter correlação com os perfis comportamentais apresentados. Assim, para atingir os objetivos propostos pela pesquisa foram aplicados questionários em 104 organizações de diferentes portes e segmentos de atuação. Os resultados da pesquisa podem ser úteis tanto para a academia, já que preenchem um gap relacionado à atuação na área de Controladoria, quanto para o mercado, uma vez que exploram o perfil comportamental de controllers de empresas nacionais.

\section{REVISÃO DA LITERATURA}

\subsection{CONTROLADORIA}

O conceito de controle é tratado com frequência pela literatura. Contudo, as formas empregadas para isto nem sempre permitem visualizar as conexões existentes entre as diferentes situações em que ele é empregado. Nesse sentido, é comum se referir ao processo de gestão, o planejamento e a sua execução para expressar um tipo de controle organizacional. Não obstante, o termo também é aplicado a outras situações, como, por exemplo para controle contábil, de custos, interno, entre outras possibilidades (Reginato \& Nascimento, 2007).

De acordo com Siqueira e Soltelinho (2001) a demanda pelos profissionais da Controladoria no Brasil remonta à década de 1960, período em que o país presenciou um forte processo de industrialização e, consequentemente, o crescimento da complexidade organizacional, fruto das novas demandas de mercado. O grande fluxo de capital estrangeiro recebido no período, principalmente de multinacionais norte-americanas, solidificou a cultura de se pensar o controle da entidade como um processo fundamental para garantir patamares adequados de desenvolvimento em contextos, nacional e internacional, cada vez mais competitivos.

Nesse cenário, a Controladoria pode ser vista tanto como um ramo do conhecimento humano quanto uma área administrativa (Catelli, 2001). Enquanto área do conhecimento, a 
Controladoria refere-se ao conjunto de saberes relacionados às práticas capazes de promover a saúde econômico-financeira das organizações, a fim de permitir melhores desempenhos de curto, médio e longo prazos. Como área administrativa, foco desse estudo, a Controladoria conta com vertentes, instrumentos, ferramentas ou dimensões de controle. Nessa linha, a área visa assegurar que os resultados econômico-financeiros da empresa sejam alcançados e, para tanto, lança mão de diversas estratégias e ferramentas de gestão (Reginato \& Nascimento, 2007). Sob essa perspectiva os objetivos da área relacionam-se à promoção da eficácia organizacional, à viabilização da gestão econômica e à interação das áreas, visando a obtenção de sinergia que otimize e conduza a empresa a um resultado econômico global que assegure a sua continuidade (Mosimann \& Fish, 1999).

O controle pode ser visualizado sob várias dimensões, tais como a físico-financeira, que compreende o sistema de informações da empresa, necessário para, conforme Catelli (2001), permitir que a área de Controladoria exerça suas atividades de forma plena. Esse controle incorpora todos os componentes do banco de dados físicos e econômicos da empresa, entre os quais o contábil, o de custos, o fiscal e o de ativo (Heckert \& Willson, 1963).

Nesta perspectiva, o controle contábil utiliza todos os registros dos eventos oriundos das transações ocorridas na organização, transformando-os em informações úteis para a evidenciação da real situação do negócio (Atkinson et al., 2000). Já o controle de custos abarca o planejamento e evolução do rendimento, a determinação dos preços, a valorização dos estoques e sua manutenção, e o controle de todos os gastos da organização (RoehlAnderson \& Bragg, 1996). O controle fiscal, por sua vez, abarca todas as questões pertinentes à figura do planejamento tributário nas organizações. Por fim, o controle de ativo abrange critérios de imobilizações, depreciações, amortizações e exaustões, além das reavaliações que compõem o ativo fixo, e demais operações relacionadas a caixa, recebimentos, estoques e investimentos (Heckert \& Willson, 1963).

Sendo assim, entre as diversas funções executadas pelos controllers, Lunkes et al. (2013), ao analisarem o contexto brasileiro, destacaram: i) o planejamento; ii) o controle; iii) a execução contábil; e iv) a elaboração de relatórios e interpretação. Vale ressaltar que o controller é um agente responsável pelo sistema de controle existente na empresa (Kanitz, 1977). A pesquisa de Zoni e Merchant (2007), por exemplo, identifica que os controllers estão envolvidos nos processos de decisão da empresa de acordo com a interdependência operacional, competência dos gestores de linha e formalização do planejamento e do orçamento, e que esse envolvimento aparece atrelado positivamente ao desempenho da empresa.

O estudo de Henttu-Aho (2016) constatou que a crescente transparência interna das práticas orçamentárias demandou que os controllers desenvolvessem novas competências, construindo uma visão holística da totalidade do controle e fornecendo informações mais relevantes no ambiente da organização. Esse resultado foi corroborado por Graham et al. 
(2012), os quais atestaram que o controller, com o tempo, passou a se preocupar mais com a gestão de todo o negócio e em agregar mais valor à empresa.

Diante desse contexto, a complexidade das tarefas exercidas pelos profissionais da controladoria, demanda um perfil de atuação profissional capaz de lidar com desafios múltiplos existentes no dia a dia das organizações. Assim, a próxima seção evidencia o constructo do perfil de atuação do Controller, considerando características comportamentais, sob a ótica de teorias do comportamento e da psicologia.

\subsection{PERFIL DE ATUAÇÃO DO CONTROLLER}

Um dos focos do comportamento organizacional é analisar as características do indivíduo, ou seja, dos seus traços de personalidade (McShane, 2014). Nesse contexto, um dos modelos com maior robustez, calcado na psicologia, é o de cinco fatores (Five Factor Model), também conhecido como Big Five, que descreve a personalidade em cinco dimensões. Nele, o fator extroversão diz respeito às definições de comunicação, energia, assertividade, timidez e comportamento reservado. Já o segundo fator, a abertura para experiência, é composto pela criatividade, intelectualidade, profundidade, inteligência, mente aberta e simples. O terceiro fator, a conscienciosidade, abarca a organização, responsabilidade, cautela e receio, instabilidade e irresponsabilidade. O fator amabilidade, por sua vez, se relaciona com o quão agradáveis e tolerantes os indivíduos tendem a ser, envolvendo confiança, simplicidade e sinceridade, altruísmo, conformidade, modéstia e empatia. Por fim, o quinto fator, neuroticismo, envolve a ansiedade, hostilidade, depressão, autoconsciência, impulsividade e vulnerabilidade (Gerrig \& Zimbardo, 2002).

Neste mesmo contexto, Bueno et al. (2001) desenvolveram uma pesquisa que correlacionou habilidades e traços de personalidade. Os resultados apontaram uma relação significativa entre enfrentamento com risco e extroversão, o que indica que os indivíduos (gestores) contemplados por traços de extroversão podem apresentar maior tendência a decisões de risco ou complexas. De acordo com Robbins (2011), as pesquisas acerca do tema demonstram que pessoas com maior extroversão, conscienciosidade e amabilidade tendem a apresentar melhor desempenho. Adicionalmente, há indícios de que pessoas com maior extroversão e conscienciosidade tendem a apresentar maior abertura a experiências, aumentando sua capacidade de liderança.

Apesar de o modelo do Big Five ser importante para entender o comportamento dos indivíduos, a literatura tem indicado outros complementos para estudos acerca do perfil comportamental em gestores. Heckert e Willson (1963), por exemplo, elencaram características fundamentais para os controllers, a saber: iniciativa, visão a longo prazo, comunicação racional, síntese, persistência, cooperação, imparcialidade, persuasão, liderança, 
ética, consciência das limitações e questões culturais. Kanitz (1977) acrescentou, ainda: motivação, coordenação, avaliação, planejamento e monitoramento. Outros estudos sobre habilidades necessárias para atuação profissional, em especial, como controller apontam para organização, adaptabilidade, iniciativa, responsabilidade, criatividade, capacidade de trabalhar em equipe, liderança, visão sistêmica, comunicação e flexibilidade (Calijuri et al., 2005; Duque, 2011; Fiirst et al., 2018; Israel et al., 2018; Ribeiro et al., 2008).

O Quadro 1 apresenta as principais características identificadas pela revisão da literatura como importantes na atuação dos gestores da controladoria. Como é possível identificar, essas características foram segregadas em duas grandes áreas: individual e interpessoal. No primeiro grupo apresentam-se: a) motivação: processo responsável pela intensidade, direção e persistência de uma pessoa para alcance da meta (Robbins, 2011); b) estresse: que pode levar à ineficiência, alta rotatividade de pessoas, aumento de custos com saúde, acidentes, diminuição da qualidade e quantidade de produção (Jex, 2014); c) tomada de decisão: capacidade de realizar escolhas dentro do processo e da estrutura organizacionais (Simon, 1965); d) extroversão, abertura para experiência e conscienciosidade: referente às características do modelo Big Five descrito anteriormente.

Quadro 1

Embasamento teórico

\begin{tabular}{|c|c|c|}
\hline Área & Características & Embasamento teórico \\
\hline \multirow{6}{*}{ Individual } & Motivação & Fiirst et al. (2018), Kanitz (1977) e Robbins (2011). \\
\hline & Estresse & Jex (2014), Kazmi et al. (2008) e Sadir e Lipp (2009). \\
\hline & Decisão & Simon (1965). \\
\hline & Extroversão & $\begin{array}{l}\text { Bueno et al. (2001), Gerrig e Zimbardo (2002), McShane (2014) e } \\
\text { Robbins (2011). }\end{array}$ \\
\hline & $\begin{array}{l}\text { Abertura para expe- } \\
\text { riência }\end{array}$ & $\begin{array}{l}\text { Bueno et al. (2001), Gerrig e Zimbardo (2002), McShane (2014) e } \\
\text { Robbins (2011). }\end{array}$ \\
\hline & Conscienciosidade & $\begin{array}{l}\text { Bueno et al. (2001), Gerrig e Zimbardo (2002), McShane (2014) e } \\
\text { Robbins (2011). }\end{array}$ \\
\hline \multirow{4}{*}{ Interpessoal } & Equipe & $\begin{array}{l}\text { Fiirst et al. (2018), Guzzo e Dickson (1996), Heckert e Willson (1963), } \\
\text { Kanitz (1977) e Robbins (2006). }\end{array}$ \\
\hline & Comunicação & $\begin{array}{l}\text { Calijuri et al. (2005), Duque (2011), Fiirst et al. (2018), Heckert e Will- } \\
\text { son (1963), Israel et al. (2018), Ribeiro et al. (2008) e Weick (1979). }\end{array}$ \\
\hline & Liderança & $\begin{array}{l}\text { Barnard (1971), Calijuri et al. (2005), Duque (2011), Fiirst et al. (2018), } \\
\text { Heckert e Willson (1963), Israel et al. (2018) e Ribeiro et al. (2008). }\end{array}$ \\
\hline & Negociação & $\begin{array}{l}\text { Acuff (1998), Calijuri et al. (2005), Duque (2011), Fiirst et al. (2018), } \\
\text { Heckert e Willson (1963), Israel et al. (2018) e Ribeiro et al. (2008). }\end{array}$ \\
\hline
\end{tabular}

Já em relação às características interpessoais, encontram-se: e) equipes: como indivíduos se percebem e são percebidos, considerando tarefas, responsabilidades e objetivos da organização (Guzzo \& Dickson, 1996); f) comunicação: processo central de uma empresa (Weick, 1979); g) liderança: influência pessoal exercida em determinada situação por meio do processo de comunicação, orientando grupos em direção a determinados objetivos (Barnard, 
1971); h) negociação: processo de comunicação com o propósito de se atingir um acordo agradável (Acuff, 1998).

\subsection{PESQUISAS EMPÍRICAS NACIONAIS ANTERIORES}

A pesquisa de Palomino e Frezatti (2016) buscou identificar o quão forte as percepções de conflito de papeis e ambiguidade nos trabalhos dos controllers brasileiros afetam sua satisfação no trabalho. Os dados foram coletados por meio de questionários, obtendo-se uma amostra de 114 instrumentos válidos, respondidos pelos próprios controllers de forma online. Por meio da estimação de equações estruturais, a pesquisa evidenciou que os profissionais da Controladoria percebem conflito e ambiguidade de função no seu trabalho, sendo o segundo problema o que mais impacta negativamente na satisfação dos controllers.

A pesquisa de Sá e Amorim (2017) buscou analisar as competências individuais utilizadas pelos profissionais de Controladoria em empresas comerciais da Região Metropolitana do Recife. Os dados foram coletados por meio da aplicação de questionários em 20 empresas de pequeno e médio porte. Por meio de uma análise descritiva e de frequências de assertivas que versaram sobre os papeis desempenhados pela Controladoria, assim como as atribuições existentes, os autores encontram evidências de que, para as empresas da amostra, não é comum a existência de uma área estruturada que executa as tarefas da área. Contudo, foi possível mapear diversas funções de controle que são utilizadas pelas entidades.

Lima e Araújo (2018) buscaram investigar os aspectos relacionados com a trajetória do Controller e, ainda, o desenvolvimento de competências necessárias à atuação na área. Para isso, os autores coletaram dados por meio de questionário, obtendo um conjunto de 208 instrumentos válidos respondidos por profissionais de diferentes níveis hierárquicos. Os resultados foram encontrados por meio de análise descritiva dos dados coletados pelo instrumento. Entre os principais achados do estudo, os autores destacaram a necessidade de ter bons níveis de conhecimento sobre temas relacionados com a Contabilidade, Finanças e Planejamento para a atuação como controller. Como competências, foram destacadas a visão estratégica e o trabalho em equipe. Sobre a formação dos profissionais, a experiência com áreas para além da contabilidade mostrou-se relevante para a trajetória dos controllers, com destaque para atuação com Auditoria e Finanças.

Silva et al. (2020) buscaram evidenciar aspectos de discriminação salarial de gênero na atuação de controllers e, ainda, descrever, por meio do discurso dos agentes, como esses profissionais percebem as práticas discriminatórias. Para isso, as autoras coletaram dados por meio de questionários ( 83 homens e 52 mulheres) e entrevistas (dois homens e duas mulheres). Os dados quantitativos foram analisados por meio de testes de médias e os qualitativos por meio da técnica de análise do discurso. Com base na investigação conduzida, 
as autoras concluíram pela presença de desigualdade de gênero no mercado para amostra de controllers analisada, o que está refletido tanto na questão salarial, quanto na atuação dos profissionais.

A investigação de Souza et al. (2020), por sua vez, apresentou três missões: i) identificar as principais tarefas desempenhadas pelos controllers no Brasil; ii) destacar um perfil predominante para esses profissionais; e iii) analisar a influência do porte e da descentralização da organização na autonomia e no envolvimento dos controllers. Por meio da aplicação de questionários via e-mail, a pesquisa obteve 111 respostas válidas. Os resultados sinalizaram, entre outras coisas, que o perfil dos controllers é marcado pela presença masculina, de pós-graduados, de indivíduos com idade, em média, de 43 anos e com 6,8 anos de experiência em Controladoria. Adicionalmente, ficou evidenciado que a descentralização possui uma associação estatisticamente significativa com o envolvimento dos controllers.

Como é possível notar, a literatura tem buscado entender, a partir de diversas abordagens e perspectivas, os fenômenos relacionados com a atuação dos profissionais da Controladoria no Brasil. O presente estudo diferencia-se de pesquisas anteriores e contribui para a evolução das pesquisas na área na medida em que acrescenta variáveis comportamentais para a análise do perfil dos controllers, bem como amostra de empresas distintas. Adicionalmente, por analisar fatores que ajudam a compreender os diferentes perfis comportamentais a presente pesquisa busca contribuir com novas abordagens metodológicas para os estudos na área.

\section{METODOLOGIA}

A presente pesquisa pode ser classificada quanto aos objetivos como descritiva, uma vez que se busca identificar a relação entre o tipo de empresa e o perfil comportamental dos controllers atuantes em empresas no Brasil. Quanto aos procedimentos e às técnicas, utilizou-se um questionário para captar os fenômenos avaliados, o qual foi respondido por 104 profissionais responsáveis pela área de Controladoria de diferentes empresas atuantes no Brasil. Por fim, quanto à abordagem do problema, a pesquisa se caracteriza como quantitativa, uma vez que foram utilizadas técnicas estatísticas e econométricas para responder ao problema proposto (Beuren, 2006).

A população-alvo da pesquisa representou empresas atuantes no Brasil que possuíam em sua estrutura organizacional a área de Controladoria. Os dados foram coletados a partir de instrumento de pesquisa preparado especialmente para este estudo, baseado na estrutura apresentada na Figura 1, o qual foi validado por 3 especialistas/professores doutores e 3 profissionais do mercado/controllers. O pré-teste foi aplicado em 15 empresas. A coleta de 
dados foi iniciada em agosto de 2019 e finalizada em julho de 2020, a partir da plataforma virtual surveymonkey.

Foram utilizadas duas estratégias para obtenção dos dados da pesquisa, ambas não probabilísticas. Para as empresas de grande porte, obteve-se o contato, junto aos responsáveis pela elaboração do ranking das Melhores \& Maiores (M\&M) da Revista Exame, de profissionais que poderiam responder pelas empresas presentes no ranking da edição de 2019 da M\&M. Já para as empresas não listadas no ranking, utilizou-se a abordagem de acessibilidade, via rede social Linkedln, a partir da identificação de potenciais respondentes atuantes na área de Controladoria. Foi permitida apenas uma resposta por empresa. A taxa de resposta geral para os questionários enviados foi de aproximadamente $25 \%$.

Nas 30 sentenças utilizadas na pesquisa os respondentes deveriam atribuir uma nota de zero a dez, de acordo com o seu grau de concordância com a afirmação, onde o limite inferior representava uma baixa concordância e o limite superior uma alta concordância. A partir desses 30 itens, foi possível construir dez índices referentes ao perfil comportamental dos participantes da pesquisa, conforme apresentado no Quadro 2 (para maiores informações sobre as sentenças, vide Tabela 3 no capítulo de Análise de Resultados). Para a criação dos índices foram somadas as pontuações atribuídas para cada uma das sentenças que compõe o respectivo indicador de análise, dividindo-se pelo número de itens que o compõe. Assim, o índice criado poderia variar de zero a dez.

Quadro 2

Construção dos itens

\begin{tabular}{|c|c|c|c|}
\hline Índice & Explicação & Nível & Sentenças \\
\hline Motivação & $\begin{array}{l}\text { Atitude de se mover pela realização das suas ativi- } \\
\text { dades desempenhadas na Controladoria }\end{array}$ & \multirow{5}{*}{ Individual } & Q1 até Q5 \\
\hline Estresse & $\begin{array}{l}\text { Comportamento negativo decorrente das experiên- } \\
\text { cias vivenciadas como controller }\end{array}$ & & Q6 até Q8 \\
\hline Decisão & $\begin{array}{l}\text { Ações relacionadas com as deliberações necessá- } \\
\text { rias para atuação na Controladoria }\end{array}$ & & Q9 até Q12 \\
\hline Extroversão & $\begin{array}{l}\text { Comportamento de sociabilidade desenvolvida } \\
\text { dentro do ambiente organizacional }\end{array}$ & & Q13 até Q15 \\
\hline $\begin{array}{l}\text { Abertura para expe- } \\
\text { riência }\end{array}$ & $\begin{array}{l}\text { Atitude relacionada com o fato de estar apto à } \\
\text { realização de novas experiências }\end{array}$ & & Q16 e Q18 \\
\hline Conscienciosidade & $\begin{array}{l}\text { Atitude de cuidado, zelo e diligência em relação às } \\
\text { atividades desempenhadas como controller }\end{array}$ & & Q19 e Q20 \\
\hline Equipe & $\begin{array}{l}\text { Comportamento desempenhado pelo indivíduo em } \\
\text { relação ao grupo no qual ele se insere }\end{array}$ & \multirow{4}{*}{ Interpessoal } & Q21 e Q22 \\
\hline Comunicação & $\begin{array}{l}\text { Atitudes desempenhadas realizadas com o objetivo } \\
\text { de tornar as decisões organizacionais mais eficien- } \\
\text { tes }\end{array}$ & & Q23 até Q25 \\
\hline Liderança & $\begin{array}{l}\text { Ações executadas como o intuito de influenciar o } \\
\text { papel desempenhado por outros na empresa }\end{array}$ & & Q26 até Q28 \\
\hline Negociação & $\begin{array}{l}\text { Comportamento realizados com o propósito de se } \\
\text { alcançar resultados favoráveis para a organização }\end{array}$ & & Q29 e Q30 \\
\hline
\end{tabular}


Para verificar a consistência interna do instrumento, estimou-se o alfa de Conbrach para as 30 sentenças do questionário, reportando o valor igual a 0,81. De acordo com Maroco e Garcia-Marques (2006), esse valor indica uma boa consistência interna, corroborando com a validação do questionário. Para a realização das análises quantitativas, foi utilizado o software Stata $3^{\circledR}$. Inicialmente, foram realizadas análises descritivas sobre os respondentes e as sentenças relacionadas com a atuação dos profissionais da Controladoria. Também foram realizadas correlações entre os índices criados, a fim de identificar relações estatisticamente significativas entre os diversos perfis comportamentais identificados. Por fim, buscando analisar possíveis fatores explicativos para os perfis comportamentais de controllers atuantes no Brasil, foram estimadas regressões lineares múltiplas, com o intuito de identificar diferenças entre o perfil comportamental dos controllers e o tipo de organização. A Equação 1 apresenta os modelos econométricos estimados com o intuito de compreender as influências para o perfil comportamental dos controllers atuantes em empresas no Brasil.

$$
Y_{i}=\beta_{0}+\beta_{1} M M_{i}+\beta_{2} \text { Gênero }_{i}+\beta_{3} \text { Idade }_{i}+\beta_{4} \text { Estado Civil }_{i}+\beta_{5} \text { Experiência }_{i}+\varepsilon_{i} \quad \text { (Equação l) }
$$

Em que, a variável explicada, representa cada um dos dez índices calculados com base nas assertivas descritas na Figura 2 e as variáveis explicativas são as que estão definidas no Quadro 3 a seguir.

Quadro 3

Variáveis explicativas das regressões lineares

\begin{tabular}{|c|c|c|}
\hline $\begin{array}{l}\text { Variáveis Ex- } \\
\text { plicativas }\end{array}$ & Significado & $\begin{array}{l}\text { Embasamento } \\
\text { Teórico }\end{array}$ \\
\hline MM & $\begin{array}{l}\text { Variável dummy que recebeu o valor } 0 \text { se a } \\
\text { empresa não estava na lista das Melhores \& } \\
\text { Maiores da Revista Exame de } 2019 \text { e } 1 \text { se estava }\end{array}$ & $\begin{array}{l}\text { Anagusko et al. (2020), Oliveira et al. } \\
\text { (2017), Sá e Amorim (2017) e Souza et al. } \\
\text { (2020). }\end{array}$ \\
\hline Gênero & $\begin{array}{l}\text { Variável dummy que recebeu o valor } 0 \text { se femi- } \\
\text { nino e } 1 \text { se masculino }\end{array}$ & $\begin{array}{l}\text { Cordeiro et al. (2018), Rengel et al. } \\
\text { (2020) e Silva et al. (2020). }\end{array}$ \\
\hline Idade & Anos de vida do controller & $\begin{array}{l}\text { Palmito e Frezatti (2016), Rengel et al. } \\
\text { (2020) e Souza et al. (2020). }\end{array}$ \\
\hline Estado Civil & $\begin{array}{l}\text { Variável dummy que recebeu o valor } 0 \text { se soltei- } \\
\text { ro(a) e } 1 \text { se casado(a), divorciado(a) ou viúvo(a) }\end{array}$ & Rengel et al. (2020). \\
\hline Experiência & $\begin{array}{l}\text { Anos em que o controller atua na entidade em } \\
\text { que se encontrava quando respondeu ao ques- } \\
\text { tionário }\end{array}$ & $\begin{array}{l}\text { Amorim et al. (2018), Fiirst et al. (2018), } \\
\text { Lima e Araújo (2018), Rengel et al. } \\
\text { (2020) e Souza et al. (2020). }\end{array}$ \\
\hline
\end{tabular}

Como é possível observar no Quadro, para diferenciar o tipo de empresa, foi criada uma variável dummy para identificar as organizações que estavam presentes na listagem da edição de 2019 da M\&M da Revista Exame (variável MM). Essa variável representa uma proxy para a complexidade da organização. As estratégias utilizadas pela Controladoria variam de acordo com a estrutura da empresa (Anagusko et al., 2020; Oliveira et al., 2017), 
- que pode demandar perfis diferentes de atuação para os profissionais da área. Além dessa variável independente, foram utilizadas as características pessoais dos participantes da amostra do estudo (Gênero, Idade, Estado Civil e Experiência), buscando identificar fatores explicativos para os perfis comportamentais identificados. Esse controle mostra-se importante porque a literatura tem identificado que características inerentes aos profissionais da área contábil-financeira estão associadas com a atuação dos indivíduos no mercado de trabalho (Amorim et al., 2018; Cordeiro et al., 2018; Fiirst et al., 2018; Palomino \& Frezatti, 2016; Rengel et al., 2020; Sá \& Amorim, 2017; Silva et al., 2020; Souza et al., 2020).

\section{ANÁLISE E DISCUSSÃO DOS RESULTADOS}

O objetivo da presente pesquisa consistiu em identificar o perfil comportamental dos controllers no Brasil. Para isso, foram aplicados questionários respondidos por 104 profissionais de empresas atuantes no país. Conforme apresentado na Tabela 1, desse montante, 7 (7\%) afirmaram ocupar o cargo de Chief Financial Officer (CFO) quando responderam ao instrumento do estudo, 21 (20\%) declararam exercer a função gerente de contabilidade, 29 (28\%) atuavam como gerente de Controladoria, 13 (12\%) como gerente financeiro, 10 (10\%) como coordenador de Controladoria, 3 (3\%) como coordenador financeiro, 3 (3\%) como coordenador de Controladoria e 18 (17\%) ocupavam outras funções relacionadas com a Controladoria. Para esse último grupo, quando questionado qual o cargo que ocupava, foram registradas diversas classificações como consultor de controladoria, gerente de planejamento econômico e financeiro, diretor de contabilidade e fiscal e diretor de controladoria. Pesquisas anteriores que analisaram a estrutura hierárquica na qual o controller se insere também sinalizaram para uma multiplicidade de classificações (Israel \& Vasconcelos, 2018; Ribeiro et al., 2008). Dessa forma, após a análise dos cargos indicados, assim como da experiência profissional dos participantes, chegou-se à conclusão de que todos os 104 respondentes estavam aptos a participarem do estudo.

Tabela 1

Composição dos cargos ocupados pela amostra da pesquisa

\begin{tabular}{lll}
\hline Cargo & Frequência Absoluta & Frequência Relativa \\
\hline CFO & 7 & $7 \%$ \\
\hline Gerente de Contabilidade & 21 & $20 \%$ \\
\hline Gerente de Controladoria & 29 & $28 \%$ \\
\hline Gerente Financeiro & 13 & $12 \%$ \\
\hline Coordenador de Controladoria & 10 & $10 \%$ \\
\hline Coordenador Financeiro & 3 & $3 \%$ \\
\hline Supervisor de Controladoria & 3 & $3 \%$ \\
\hline Outro & 18 & $17 \%$ \\
\hline
\end{tabular}


$\mathrm{Na}$ Tabela 2 estão apresentadas as informações socioeconômicas sobre os participantes da pesquisa relacionadas à idade (média em anos), experiência do profissional na empresa em que atua (média em anos), gênero (frequência), estado civil (frequência). Como é possível perceber, em média, os respondentes apresentavam 43 anos quando responderam ao questionário e apresentavam 10,2 anos de experiência na empresa. Pode-se perceber, ainda, uma alta amplitude para as variáveis contínuas. A variável Idade, por exemplo, valor mínimo de 26 e máximo de 71. Já para a variável Experiência, relacionada com o tempo de trabalho que o indivíduo tinha na empresa que apresentava vínculo quando respondeu a pesquisa, foi possível identificar um valor mínimo de 1 e máximo de 40 . A diferença entre essas duas primeiras variáveis recai no fato de que a Idade permite captar toda a vivência do participante e a variável Experiência diz respeito exclusivamente às experiências do indivíduo na empresa em que se encontrava quando respondeu o questionário.

A amostra é marcada também por uma maior presença do gênero masculino $(73,1 \%)$, - que está em linha com outras pesquisas brasileiras que já identificaram uma menor presença de mulheres no topo da carreira na área contábil-financeira (Cordeiro et al., 2018; Rengel et al., 2020), além das dificuldades já mapeadas para o desenvolvimento feminino na área da Controladoria (Silva et al., 2020). Além disso, é possível notar maior presença de participantes não solteiros (o que inclui os casados, em união estável, divorciados e viúvos), em linha com a idade média dos respondentes.

A Tabela 2 contém a informação sobre o tipo de empresa na qual o respondente trabalhava. Como é possível notar, a maior parte dos respondentes (59,6\%) estava inserida em organizações listadas na edição de 2019 da MM. Esse tipo de organização tende a apresentar maior complexidade em suas atividades, em decorrência do porte e desempenho econômico, o que pode demandar comportamentos distintos por parte dos profissionais da área da Controladoria.

Tabela 2

Características dos respondentes

\begin{tabular}{lccrr}
\hline \multicolumn{1}{c}{ Variáveis Contínuas } & Média (em anos) & Desvio Padrão & Valor Máximo & \multicolumn{2}{c}{ Valor Mínimo } \\
\hline Idade & 43,0 & 8,6 & 26 & 71 \\
\hline Experiência & 10,2 & 9,1 & 1 & 40 \\
\hline \multicolumn{1}{c}{ Variáveis Dummy } & Frequência Absoluta & & Frequência Relativa & \\
\hline Gênero & & & & $73,1 \%$ \\
\hline Masculino & 76 & $26,9 \%$ \\
\hline Feminino & 28 & \\
\hline Estado Civil & & $24.0 \%$ \\
\hline Solteiro & 25 & $76.0 \%$ \\
\hline Não solteiro & 79 & \\
\hline Tipo de Empresa & & & \\
\hline Listada MM & 62 & $59,6 \%$ \\
\hline Não listada MM & 42 & $40,4 \%$ \\
\hline
\end{tabular}


$\mathrm{Na}$ Tabela 3 estão apresentadas as análises descritivas construídas para 30 sentenças que foram utilizadas na construção dos índices utilizados na pesquisa. Como é possível notar, todas as sentenças que compõe o índice da Motivação ( $Q 1$ até Q5) apresentaram médias maiores do que 7, com desvio padrão variando entre 1.45 e 2,31. De uma forma geral, podese notar que os respondentes da pesquisa mostraram níveis de motivação elevados para a atuação profissional na área em que estão inseridos. De acordo com a literatura, a motivação é um importante fator para o desempenho profissional dos indivíduos. Quanto mais motivado - funcionário está, melhor tende a ser o desempenho da organização (Robbins, 2006). Portanto, esse resultado se mostra alinhado com a literatura.

Já as três sentenças voltadas para o índice de Estresse (Q6 até Q8) apresentaram médias iguais a 2,50, 4,37 e 2,28, respectivamente. É importante notar que duas das três sentenças usadas para criar o índice de Estresse passaram pela reversão de valores para mostrarem uma direção consistente. Dessa forma, quanto maior o índice de Estresse, pior tende a ser a atuação dos profissionais na empresa (Jex, 2014; Kazmi et al., 2008; Sadir \& Lipp, 2009).

Ainda analisando os resultados evidenciados na Tabela 3, é possível notar que todas as assertivas relacionadas com o índice relacionado ao comportamento da Decisão (Q9 até Q12) obtiveram médias maiores do que 8 , indicando que os controllers participantes da pesquisa apresentaram alta maturidade profissional. Esse resultado pode estar relacionado com o fato de os participantes da pesquisa estarem em cargos elevados dentro de suas estruturas organizacionais, os quais, para serem ocupados, necessitam de desenvolvimento de habilidades relacionadas à tomada de decisão. Esse resultado mostrou concordância com Simon (1965), o qual afirmou que quanto menos níveis hierárquicos existirem para que um assunto transite até a sua decisão final, maior a eficiência na empresa. Isso significa também que os profissionais investigados possuem autonomia e as empresas em que atuam tendem a evidenciar processos descentralizados quando se trata de cargo de alta gestão.

Tabela 3

Análise descritiva dos itens do instrumento

\begin{tabular}{|c|c|c|c|c|c|c|}
\hline Sentenças & Média & Med. & Moda & Desv. Pad. & Mín. & Máx. \\
\hline $\begin{array}{l}\text { Q1. Quando a empresa atribui a mim aumento de salário } \\
\text { ou recompensa financeira com base no resultado do meu } \\
\text { trabalho, sinto vontade de desenvolver mais ainda as mi- } \\
\text { nhas funções e até brinco com meus colegas }\end{array}$ & 8,03 & 9 & 10 & 2,12 & 0 & 10 \\
\hline $\begin{array}{l}\text { Q2. Ao conseguir visualizar cenários promissores para a } \\
\text { empresa em que atuo, comento com entusiasmo sobre } \\
\text { esse quadro com meus pares no trabalho e também com } \\
\text { amigos e familiares }\end{array}$ & 8,08 & 8 & 9 & 1,76 & 0 & 10 \\
\hline
\end{tabular}


Média Med. Moda Desv. Pad. Mín. Máx.

Q3. Em momentos de instabilidade na empresa, seja econômica ou ocasionada por outras variáveis, que pode me afetar de alguma forma, reúno forças, mantenho e até melhorou meu desempenho

Q4. Percebo que as responsabilidades são a mim designadas de acordo com a minha habilidade de controlar meu comportamento

$\begin{array}{llllll}8,10 & 8 & 8 & 1,84 & 0 & 10\end{array}$

Q5. Elogios relacionados às minhas funções e à minha postura, bem como a projeção de meu nome e minha imagem, são elementos suficientes para melhorar o meu desempe8,5

$\begin{array}{llllll}8,55 & 9 & 10 & 1,45 & 3 & 10\end{array}$
nho na empresa

Q6. Julgo as demandas no meu ambiente de trabalho na medida certa e compatíveis com os recursos que possuo para executá-las*

Q7. Percebo alta rotatividade de pessoas em minha empresa

Q8. Sinto-me privilegiado por atuar na minha empresa, pois há valorização da saúde e da qualidade de vida dos funcionários*

Q9. Quando tenho que tomar uma decisão, antes reúno todas as informações necessárias para uma análise completa

Q10. Ao ser solicitado para avaliar e decidir sobre o fechamento de uma unidade da empresa, assumo plenamente a designação e viso o impacto dessa decisão no sistema todo

Q11. Sempre que tenho que tomar uma decisão importante eu converso com meus pares e outras pessoas envolvidas, e só depois disso chego a conclusões

Q12. Crio cenários distintos e insiro diversas variáveis em caso de ter que tomar uma decisão, a ponto de meus colegas comentarem que "tenho visão"

Q13. Gosto muito de conversar durante as horas de trabalho e fora dele

$\begin{array}{llllll}7,16 & 8 & 8 & 2,31 & 0 & 10\end{array}$

Q14. Quando percebo algo a fazer, imediatamente me dis-

ponho ou encontro uma forma de fazê-lo, não esperando que me solicitem

$\begin{array}{llllll}2,50 & 2 & 1 & 2,14 & 0 & 10\end{array}$

$\begin{array}{llllll}4,37 & 4 & 2 & 2,95 & 0 & 10\end{array}$

$\begin{array}{llllll}2,28 & 2 & 1 & 2,15 & 0 & 10\end{array}$

$\begin{array}{llllll}8,96 & 9 & 9 & 0,92 & 6 & 10\end{array}$

$\begin{array}{llllll}8,14 & 8 & 8 & 1,72 & 0 & 10\end{array}$

Q15. Nas reuniões em grupos, especialmente nos momentos

em que tenho que apresentar para pares e superiores os resultados individuais, da equipe e da empresa, me sinto à

8,14

8

$8 \quad 1,35$
vontade e teço comentários espontâneos

Q16. A empresa anuncia que abrirá nova unidade e necessita de gestores competentes e que gostem de desafios para atuar nesse empreendimento. Eu me coloco à disposição para assumir o cargo

Q17. A estrutura da empresa será enxugada devido a novas diretrizes dos proprietários. Ao saber disso, imediatamente penso em alternativas e abro busca por novas oportunidades

Q18. Encontro facilmente documentos arquivados quando os procuro, seja física ou eletronicamente

$\begin{array}{llllll}6,31 & 7 & 8 & 2,19 & 0 & 10\end{array}$

$\begin{array}{llllll}8,39 & 9 & 9 & 1,44 & 3 & 10\end{array}$

Q19. Dificilmente atraso a entrega de algum relatório ou outro trabalho sob minha responsabilidade

$\begin{array}{llllll}7,59 & 8 & 9 & 2,19 & 0 & 10\end{array}$

Q20. As pessoas da minha equipe atuam sempre coletivamente, compartilhando informações e resultados

$\begin{array}{llllll}6,91 & 7 & 8 & 2,19 & 1 & 10 \\ 8,18 & 8 & 8 & 1,52 & 2 & 10 \\ 8,70 & 9 & 9 & 1,26 & 5 & 10 \\ 8,36 & 9 & 9 & 1,21 & 5 & 10\end{array}$


Q21. Em reuniões de diretoria eu costumo mencionar o nome dos membros da equipe que realizaram determinadas tarefas e também comento sobre os êxitos logrados $\begin{array}{llllll}8,92 & 9 & 10 & 1,06 & 5 & 10\end{array}$ por todos

Q22. Costumo saber sobre mudanças que ocorrerão em minha área antes de serem comunicadas publicamente pelos superiores

Q23. Sinto-me mais à vontade para dialogar, e de fato dialogo, com meus pares do que com subordinados ou superiores*

Q24. Percebo que nem todas as pessoas na empresa dialogam como deveriam para que os processos fluam adequadamente

Q25. As metas usualmente necessitam ser pensadas e revisadas e eu participo do processo junto com meus pares

e, também, chamo meus subordinados a participarem ou

$\begin{array}{lll}7,66 & 8 & 9\end{array}$

2,23

$0 \quad 10$ opinarem

Q26. Tenho liberdade e flexibilidade para gerir a minha área e a minha equipe da forma como eu julgar mais conveniente

4,22

3

3

3,02

$0 \quad 10$

Q27. A mim são comunicadas as decisões sobre planejamento $e$, consequentemente, tenho que providenciar a execução e o controle

Q28. A atuação dos líderes da empresa afeta o meu desempenho*

$\begin{array}{llll}7,79 & 8 & 8 & 1,86\end{array}$

1,86

210

Q29. A área financeira é incumbida de discutir um contrato complexo com o banco, cujo resultado pode impactar o plano do negócio. Eu ofereço participação ativa para alcançar a melhor negociação

Q30. Na empresa em que atuo há uma política bem definida em relação à carreira. Quando um cargo é colocado à disposição, os melhores se destacam naturalmente e 7,95

$7,63 \quad 8$

8

$0 \quad 10$ ocupam-no

\footnotetext{
*Sentenças que sofreram a reversão de valores para a construção dos índices
}

As sentenças relacionadas com o índice de Extroversão ( 013 até Q15), por sua vez, mostraram que apenas $Q 13$ apresentou média inferior à 7 . As duas outras sentenças que compõe o índice Extroversão apresentaram médias maiores do que 8 e desvio padrão de 1,44 e 1,51, indicando bons níveis de extroversão para os respondentes da amostra do estudo. De acordo com a literatura, há indícios de que indivíduos mais extrovertidos conseguem tomar decisões de maior risco e complexidade (Bueno et al., 2001). O resultado da Q15 pode ser explicado à medida que o profissional da área de Controladoria pode, em muitos momentos, estar centrado em suas funções, não priorizando longas ou frequentes conversas durante o trabalho, e mesmo fora (caso o comportamento seja mais reservado) (Gerrig \& Zimbardo, 2002).

As duas sentenças utilizadas para mensurar o índice de Abertura para novas experiência (Q16 e Q18) revelaram valores médios de 7,59 e 6,91 e desvio padrão de 2,19. Comparados 
com os resultados obtidos para outros índices, esses números sinalizam que os participantes da amostra da pesquisa apresentaram uma baixa abertura para novas experiências. As sentenças do índice de Conscienciosidade ( 019 e Q20), por sua vez, apresentaram valores médios maiores do que 8 , sinalizando que os respondentes apresentam um bom nível de cuidado e diligência em suas atividades profissionais, o que se torna cada vez mais necessário para o desempenho das funções de um controller nas organizações (Frenay, 2017).

Por fim, ainda em relação aos dados apresentados na Tabela 3, é possível notar que as sentenças que formam os índices relacionados com o comportamento interpessoal (Equipe, Comunicação, Liderança e Negociação) apresentaram resultados mais baixos, com exceção das assertiva Q21 e Q22 utilizadas para mensurar o índice Equipe, que apresentou valores médios maiores do que 8. De acordo com a literatura, saber gerir e comandar equipes são atitudes fundamentais para a atuação como controller (Amorim et al., 2018; Nascimento \& Reginato, 2010). Esse resultado indica que, no que diz respeito ao comportamento em grupo, o controller deve focar em seu desenvolvimento ou aperfeiçoamento.

A Tabela 4 contém a correlação estabelecida entre os dez índices construídos pela pesquisa. O teste de normalidade Shapiro-Wilk indicou que apenas para "Comunicação" e "Liderança" não é possível rejeitar a hipótese nula de que há uma distribuição gaussiana. Dessa forma, optou-se por estimar a correlação por meio do teste de Spearman, aplicável para situações em que não há distribuição normal dos dados (Andrés et al., 1995).

Como é possível notar, diversos índices mostraram correlação estatisticamente significativas ao nível de 1\%, 5\% ou 10\%. O índice de Extroversão, por exemplo, mostrou correlação estatisticamente significativa com todos os demais, exceto com os índices de Comunicação e Negociação. Já para o índice de Negociação não houve correlação estatisticamente significativa apenas com a já mencionada Extroversão e Comunicação. $\bigcirc$ índice Abertura, por sua vez, só não apresentou correlação estatisticamente significativa com o índice Equipe, Comunicação e Liderança. $O$ índice de motivação foi o único que apresentou significância estatística com todos os demais, pelo menos ao nível de $10 \%$. 
Tabela 4

Correlação entre os índices

\begin{tabular}{|c|c|c|c|c|c|c|c|c|c|}
\hline Índices & (1) & (2) & (3) & (4) & (5) & (6) & (7) & (8) & (9) \\
\hline Motivação (1) & 1,00 & & & & & & & & \\
\hline Estresse (2) & $-0,17^{*}$ & 1,00 & & & & & & & \\
\hline Decisão (3) & $0,23^{* *}$ & $-0,24^{* *}$ & 1,00 & & & & & & \\
\hline Extroversão (4) & $0,49^{* * *}$ & $-0,30^{* * *}$ & $0,43^{* * *}$ & 1,00 & & & & & \\
\hline Abertura (5) & $0,20^{* *}$ & $-0,20^{* *}$ & $0,30^{* * *}$ & $0,41^{* * *}$ & 1,00 & & & & \\
\hline $\begin{array}{l}\text { Conscienciosidade } \\
\text { (6) }\end{array}$ & $0,18^{*}$ & $-0,26^{* * *}$ & $0,40^{* * *}$ & $0,38^{* * *}$ & $0,23^{*}$ & 1,00 & & & \\
\hline Equipe (7) & $0,31^{* * *}$ & $-0,16$ & $0,35^{* * *}$ & $0,30^{* * *}$ & 0,14 & $0,37^{* * *}$ & 1,00 & & \\
\hline Comunicação (8) & $0,21^{* *}$ & 0,04 & 0,10 & 0,16 & $-0,07$ & 0,14 & $0,29^{* * *}$ & 1,00 & \\
\hline Liderança (9) & $0,28^{* * *}$ & $-0,33^{* * *}$ & $0,21^{* *}$ & $0,21^{* *}$ & 0,06 & $0,27^{* * *}$ & $0,37^{* * *}$ & $0,28^{* * *}$ & 1,00 \\
\hline Negociação (10) & $0,31^{* * *}$ & $-0,31^{* * *}$ & 0,14 & $0,31^{* * *}$ & $0,22^{* *}$ & $0,23^{* *}$ & $0,23^{* *}$ & 0,03 & $0,34^{* * *}$ \\
\hline $\begin{array}{l}{ }^{* * *} \text { significativo a } 1 \%, \\
{ }^{* *} \text { significativo a } 5 \% \text { e } \\
{ }^{*} \text { significativo a } 10 \%\end{array}$ & & & & & & & & & \\
\hline
\end{tabular}

Para o índice de Estresse foi possível obter uma correção estatisticamente significativa com Motivação, Decisão, Extroversão, Abertura, Conscienciosidade, Liderança e Negociação. Para todas as correlações estatisticamente significativas do índice de Estresse, foi observado um sinal negativo, indicando uma relação inversamente proporcional, conforme apontado pela revisão da literatura (Jex, 2014; Kazmi et al., 2008; Sadir \& Lipp, 2009). Nesse contexto, os resultados obtidos para a correlação entre os índices apresentados na Tabela 4, além de indicar uma proximidade entre os diversos perfis comportamentais, corroboram com a validação interna do instrumento utilizado no estudo.

Nas Tabelas 5 e 6 estão apresentados os resultados encontrados para as regressões lineares múltiplas realizadas para cada um dos índices estimados pela pesquisa. Em todas as regressões, foram utilizadas as variáveis explicativas descritas na Figura 3, alterando-se apenas a variável dependente. 
Tabela 5

Regressões múltiplas para os índices de comportamento

\begin{tabular}{lcccccr}
\hline \multirow{2}{*}{ Coeficientes } & \multicolumn{7}{c}{ Índices (variável dependente) } \\
\cline { 2 - 7 } Constante & Motivação & Estresse & Decisão & Extroversão & Abertura & Conscienciosidade \\
\hline MM & $0,8155^{* * *}$ & $0,5375^{* * *}$ & $0,7161^{* * *}$ & $0,6343^{* * *}$ & $0,6753^{* * *}$ & $0,7894^{* * *}$ \\
\hline Gênero & 0,0172 & $-0,0241$ & $-0,0057$ & 0,0443 & $-0,0072$ & $-0,0105$ \\
\hline Idade & $-0,0319$ & $-0,0093$ & 0,0305 & $-0,0122$ & $-0,0550$ & $-0,0220$ \\
\hline Estado Civil & $-0,0012$ & $-0,0041^{*}$ & $0,0030^{* *}$ & $0,0028^{*}$ & 0,0019 & 0.0020 \\
\hline Experiência & $0,0652^{*}$ & 0,0161 & $-0,0187$ & $-0,0307$ & 0,0320 & $-0,0317$ \\
\hline Teste F & $-0,0001$ & $-0,0046^{* *}$ & $-0,0004$ & 0,0184 & $-0,0013$ & 0,0016 \\
\hline $\mathrm{R}^{2}$ Ajustado & 0,4093 & $0.0078^{* * *}$ & $0,0496^{* *}$ & 0.1270 & 0.4452 & 0.2149 \\
\hline Teste VIF & 0,0606 & 0,1288 & 0,0782 & 0.0929 & 0.0352 & 0.0553 \\
\hline Obs. & & & & 1,16 \\
\hline$* * *$ & & & & 104 \\
\hline
\end{tabular}

Para fins de apresentação, na Tabela 4 estão apresentados os índices internos e a Tabela 6 com os índices interpessoais, de acordo com a separação apresentada na Figura 1. Como é possível notar, apenas para quatro índices foi possível identificar um modelo que, de acordo com o Teste $F$, apresentasse significância estatística ao nível de, pelo menos, $5 \%$. Para todas as estimações foi utilizada a correção robusta de White para a heterocedasticidade.

A leitura da Tabela 5 indica que a regressão estimada para o índice de Estresse retornou duas variáveis com significância estatística de, pelo menos, 10\%. A variável Experiência mostra que quanto mais tempo o profissional da Controladoria está na instituição, menor tende a ser o índice de Estresse. Essa evidência pode indicar que o aprendizado sobre a empresa (tempo de experiência na entidade) permite uma atuação com uma menor presença de estresse para os controllers. Esse resultado está em linha com achados de outras pesquisas que destacaram a experiência profissional na área como uma característica importante para a atuação como controller nas mais diversas entidades (Amorim et al., 2018; Fiirst et al., 2018; Lima \& Araújo, 2018; Rengel et al., 2020; Souza et al., 2020).

A variável Idade, por sua vez, indica que profissionais mais velhos também tendem a apresentar menor estresse em sua atuação na Controladoria. Mais uma vez, tem-se a possibilidade de a experiência (dessa vez relacionada com a idade do indivíduo e não com o tempo de atuação na organização) gera um know how de atuação que reduz o estresse percebido pelo profissional. A variável Idade ainda mostrou ser estatisticamente significativa (ao nível de 5\%) na regressão estimada para o índice de Decisão. $O$ coeficiente positivo obtido indica que profissionais mais velhos tendem a apresentar maior poder de tomada de decisão, o que também pode ter relação direta com as experiências que o indivíduo acumula ao longo da vida profissional. Essa evidência vai ao encontro de pesquisas anteriores que 
apontaram que os responsáveis pela controladoria nas entidades tendem a ser profissionais mais velhos (Palmito \& Frezatti, 2016; Rengel et al., 2020; Souza et al., 2020).

A análise da Tabela 6 indica que, para o índice de Comunicação, a variável Experiência mostrou uma relação inversamente proporcional, indicando que profissionais com mais tempo de casa tendem a apresentar um menor índice de Comunicação. Esse resultado é contrário ao que se esperava a partir da revisão de literatura, uma vez que a experiência obtida na própria organização deveria auxiliar o indivíduo a se comunicar melhor. $O$ resultado obtido para a variável Estado Civil, significativa a 10\%, indica que os não solteiros tendem a apresentar uma capacidade de comunicação menor do que os solteiros. Esse resultado pode indicar um perfil mais sociável dos respondentes do segundo grupo, o que tende a favorecer as habilidades de Comunicação. Além disso, a variável MM, significativa a 10\%, indica que os controllers participantes da pesquisa que estavam atuando em empresas listadas na M\&M de 2019 da Revista Exame mostraram maior capacidade de comunicação do que seus pares atuantes em organizações não listadas. Esse resultado pode estar capturando uma diferença existente entre entidades de maior e menor complexidade, conforme destaca a literatura (Anagusko et al., 2020; Oliveira et al., 2017; Sá \& Amorim, 2017; Souza et al., 2020). Por fim, a variável Idade, significativa a $10 \%$, indica que profissionais mais velhos tendem a apresentar melhor capacidade de comunicação, sinalizando que as experiências adquiridas com a idade tendem a favorecer a atuação como controller (Palmito \& Frezatti, 2016; Rengel et al., 2020; Souza et al., 2020).

A última regressão estatisticamente significativa foi obtida para o índice de Negociação. Como é possível notar pela análise da Tabela 6, a variável Idade, significativa a $1 \%$, indicou que quanto mais velho o controller, maior, em média, a sua capacidade de negociação. Essa evidência também está em linha com os achados de pesquisas anteriores, sinalizando que as experiências absorvidas pelo indivíduo ao longo da vida (representação da proxy para Idade) auxiliam no desenvolvimento de habilidades necessárias para a atuação como controller (Palmito \& Frezatti, 2016; Rengel et al., 2020; Souza et al., 2020). 
Tabela 6

Regressões múltiplas para os índices de comportamento

\begin{tabular}{|c|c|c|c|c|}
\hline \multirow{2}{*}{ Coeficientes } & \multicolumn{4}{|c|}{ Índices (variável dependente) } \\
\hline & Equipe & Comunicação & Liderança & Negociação \\
\hline Constante & $0,7973^{* * *}$ & $0,5997^{* * *}$ & $0,5316^{* * *}$ & $0,4089^{* * *}$ \\
\hline MM & 0,0193 & $0,0476^{*}$ & 0,0299 & 0,0569 \\
\hline Gênero & 0.0003 & $-0,0232$ & $-0,0361$ & 0,0571 \\
\hline Idade & 0,0012 & $0,0027^{*}$ & 0,0031 & $0,0063^{* * *}$ \\
\hline Estado Civil & 0,0188 & $-0,0493^{*}$ & 0.0125 & $-0,0597$ \\
\hline Experiência & $-0,0013$ & $-0.0034^{* * *}$ & $-0,0019$ & $-0,0036^{*}$ \\
\hline Teste F & 0.5685 & $0.0128^{* *}$ & 0.2859 & $0.0354^{* *}$ \\
\hline $\mathrm{R}^{2}$ Ajustado & 0.0309 & 0.1212 & 0.0634 & 0.0954 \\
\hline Teste VIF & & & & 1,16 \\
\hline Obs. & & & & 104 \\
\hline
\end{tabular}

Em contrapartida, a variável Experiência, relacionada com o tempo de atuação do profissional na empresa que estava atuando quando participou da pesquisa, mostrou, ao nível de significância de 10\%, que profissionais com mais tempo de casa tendem a apresentar menor capacidade de negociação. Esse resultado, em específico, é contrário às evidências da literatura, uma vez que era esperado que profissionais com mais tempo de casa apresentassem maiores habilidades de negociação com os demais colaboradores. Os resultados obtidos para a variável Experiência nas regressões para Comunicação e Negociação, ambos opostos ao esperado pela literatura, podem, portanto, indicar problemas relacionados com o comodismo que pode emergir com o passar do tempo no trabalho.

\section{CONCLUSÃO}

A presente pesquisa teve como objetivo identificar o perfil comportamental dos controllers no Brasil. Para isso, utilizou-se como estratégia de coleta de dados a aplicação de um questionário, elaborado com base na revisão da literatura. Ao todo, a pesquisa contou com a participação de 104 profissionais de Controladoria atuantes em diferentes organizações do país em nível de gestão/estratégia. Para analisar os dados, foram utilizadas técnicas de análise descritiva, estimação de correlações e regressões lineares múltiplas. A partir desses procedimentos, foram encontradas evidências relevantes para a atuação dos controllers.

Em primeiro lugar, pode-se notar que os controllers participantes do estudo apresentaram um comportamento em linha com o que foi apresentado pela literatura. $A$ partir dos procedimentos realizados pela pesquisa, foi possível identificar bons níveis de 
atitudes esperadas para os profissionais da área, como motivação para o trabalho, poder de tomada de decisão, conscienciosidade e trabalho em equipe. Em contrapartida, apesar de não ser divergente da literatura para profissionais em nível de gestão/estratégia, pode-se notar a presença de comportamentos geradores de estresse nos participantes do estudo, o que tende a gerar problemas para a atuação futura destes profissionais e, até mesmo, para a sua saúde física e mental.

Em relação aos fatores explicativos para as diferenças comportamentais observadas para a amostra da pesquisa, foi possível notar que a experiência profissional do controller na empresa em que atuava quando da participação no estudo, assim como a sua idade (proxy para experiência profissional geral), apresentaram maior poder explicativo nas regressões lineares múltiplas estimadas. A pesquisa identificou, ainda, que não há diferenças estatisticamente significativas entre o perfil comportamental dos profissionais de Controladoria de empresas da amostra listadas na M\&M da Revista Exame (uma proxy para complexidade organizacional) e aqueles provenientes de empresas não listadas. A única exceção a esta evidência foi observada para o perfil comportamental relacionado com a Comunicação. Também não foram identificadas, para a amostra do estudo, diferenças estatisticamente significativas entre o perfil comportamental de controllers do gênero masculino e feminino, o que é importante em um contexto ainda marcado pela presença de desigualdade de gênero (Silva et al., 2020).

O estado civil, por sua vez, apresentou significância estatística apenas para explicar as variações no comportamento para a motivação e para a comunicação dos profissionais de Controladoria da amostra. Para o primeiro caso, os profissionais solteiros apresentaram resultados inferiores aos não solteiros. Para o segundo caso, a relação encontrada foi oposta, ou seja, os controllers solteiros apresentaram melhor comunicação quando comparados com os não solteiros. Acredita-se que esses resultados podem ter relação direta com o próprio perfil apresentado pelos grupos. Profissionais não solteiros podem ter uma maior necessidade de estabilidade profissional, em função de demandas familiares, por exemplo, impactando nos níveis de motivação. Já os profissionais solteiros, pelo próprio estilo de vida podem apresentar maior facilidade de comunicação em um contexto global.

Os resultados desta investigação ajudam a compreender melhor a atuação dos profissionais da Controladoria no Brasil, contribuindo com a literatura sobre o tema. Sob a ótica de ensino, pode-se realizar reflexões importantes acerca da formação de futuros profissionais da Controladoria, os quais devem possuir habilidades pessoais e interpessoais bem desenvolvidas para uma boa atuação no mercado de trabalho. Do ponto de vista das organizações, conhecer o perfil apresentado pelos controllers pode impulsionar incentivos para o desenvolvimento pessoal e profissional desses colaboradores, contribuindo, em última instância, para o desempenho da empresa. 
Não obstante, algumas limitações de pesquisa precisam ser destacadas. Em primeiro lugar, tem-se a não aleatoriedade da amostra, o que impossibilita a generalização de resultados. A análise comportamental dos controllers realizada a partir de questionário também possui como limitação a impossibilidade de se alcançar uma maior profundidade nas informações coletadas. Assim, para pesquisas futuras, sugere-se a realização de estudos sobre a temática com abordagem qualitativa, de forma a complementar as evidências da presente investigação.

\section{REFERÊNCIAS}

Acuff, F. L. (1998). Como negociar qualquer coisa com qualquer pessoa em qualquer lugar do mundo. São Paulo: Senac.

Amorim, T. N. G. F., Oliveira, A. R. L., Manzi, S. M. S., \& Bemfica, M. F. C. (2018). Perfil e competências do controller em empresas no Recife. Revista Mineira de Contabilidade, 19(3), 52-63. https://doi.org/10.21714/2446-9114RMC2018v19n3t05.

Anagusko, L. H., Araki, M. E., \& Moser, E. M. (2020). Implantação da controladoria em micro e pequenas empresas no Brasil: o que considerar? Revista da Micro e Pequena Empresa, 14(1), 59-78. http://dx.doi.org/10.21714/19-82-25372020v14nlp5978.

Andrés, A. M., Tejedor, I. H., \& Mato, A. S. (1995). The Wilcoxon, Spearman, Fisher, X2, Student and Pearson tests and $2 \times 2$ tables. The Statistician, 44(4), 44l-450. https://doi. org/10.2307/2348893.

Atkinson, A., Banker, R. D., Kaplan, R. S., \& Young, M. (2000). Contabilidade gerencial. São Paulo: Atlas.

Barnard, C. (1971). As funções do executivo. São Paulo: Atlas.

Beuren, I. M. (Org.). (2006). Como elaborar trabalhos monográficos em contabilidade: teoria e prática. ( $3^{a}$ ed.). São Paulo: Atlas.

Borinelli, M. L. (2006). Estrutura conceitual básica de controladoria: sistematização à luz da teoria e da práxis. [Tese de doutorado, Universidade de São Paulo, São Paulo, SP, Brasil]. https://www.teses.usp.br/teses/disponiveis/12/12136/tde-19032007-151637/publico/ Tesemarcioborinelli.pdf.

Bueno, J. M., Oliveira, S. M., \& Oliveira, J. C. (2001). Um estudo correlacional entre habilidades sociais e traços de personalidade. PsicoUSF, 6(1), 31-38. https://doi.org/10.1590/ S1413-82712001000100005.

Calijuri, M. S. S., Santos, N. M. B. F., \& Santos, R. F. (2005). Perfil do controller no contexto organizacional atual brasileiro. IX Congresso Internacional de Custos. Florianópolis. https://anaiscbc.emnuvens.com.br/anais/article/view/2102. 
Catelli, A. (Org.). (2001). Controladoria: uma abordagem da gestão econômica GECON. São Paulo: Atlas.

Cordeiro, F. A., Pereira, F. R., Durso, S. O., \& Cunha, J. V. A. (2018). Complexidade organizacional e liderança feminina nas empresas de auditoria externa. Revista Contemporânea de Contabilidade, 15(36), 31-148. http://dx.doi.org/10.5007/21758069.2018v15n36p31.

Duque, C. (2011). O perfil do controller e as funções de controladoria: um estudo da atual necessidade do mercado de trabalho. [Dissertação de Mestrado, Universidade Federal de Pernambuco, Recife]. https://repositorio.ufpe.br/handle/123456789/5023.

Fiirst, C., Lavarda, C. E. F., Pamplona, E., \& Zonatto, V. C. S. (2018). Perfil do controller e a evolução histórica da profissão no contexto brasileiro. Revista Enfoque, 37(2), 1-20. https://doi.org/10.4025/enfoque.v37i2.33342.

Frenay, L. (2017). Looking forward: the new controller roll. Master' Thesis, Radboud University, Nijmegen, Netherlands. https://theses.ubn.ru.nl/handle/123456789/5160.

Gerrig, R., \& Zímbardo, P. (2002). Psychology and life. Boston: Pearson.

Gomes, C. V., Souza, P. de, \& Lunkes, R. J. (2014). O perfil profissional da Controladoria solicitado por empresas brasileiras. Revista de Globalización, Competitividad y Gobernabilidad, 8(1), 34-50. https://www.redalyc.org/pdf/5118/511851340004.pdf.

Graham, A., Davey-Evans, S., \& Toon, I. (2012). The developing role of the financial controller: evidence from the UK. Journal of Applied Accounting Research, 13(1), 71-88. https:// doi.org/10.1108/09675421211231934.

Guzzo, R., \& Dickson, M.W. (1996). Teams in organizations: recent research on performance and effectiveness. Annual review of psychology, 47(1), 307-338. https://doi.org/10.1146/annurev.psych.47.1.307

Heckert, J. B., \& Willson, J. D. (1963). Controllership. New York: The Ronald Press Company.

Henttu-Aho, T. (2016). Enabling characteristics of new budgeting practice and the role of controller. Qualitative Research in Accounting \& Management, 13(1), 31-56. https://doi. org/10.1108/QRAM-09-2014-0058.

Israel, S. M. B., \& Vasconcelos, G. (2018). As características do controller e da controladoria no atual ambiente organizacional. Revista Fatec, 5(2), 1-18. http://revistarefas.com.br/index.php/RevFATECZS/article/view/227/188.

Jex, S.M. (2014). The important of prevalence in occupational stress research. Stress and Health, 30(2), 89-9. https://doi.org/10.1002/smi.2573.

Kanitz, S. C. (1977). Controladoria: teoria e estudos de casos. São Paulo: Livraria Pioneira. 
Kazmi, R., Amjad, S., \& Khan, D. (2008). Occupational stress and its effect on job performance. A case study of medical house officers of district Abbottabad. Journal of Ayub Medical College, 20(3) 135-139.

Leite, E. (2013). Adoção de práticas de controladoria por empresas atuantes no Brasil: um estudo sob a ótica da teoria da contingência. [Dissertação de Mestrado, Universidade do Vale do Rio dos Sinos, São Leopoldo, RS]. http://www.repositorio.jesuita.org.br/handle/UNISINOS/4312.

Lima, R. J. V. S., \& Araújo, A. O. (2018). Desenvolvimento de competências e a trajetória do controller. Revista Mineira de Contabilidade, 19(3), p. 28-40. http://www.spell.org.br/documentos/ver/52065.

Lunkes, R. J., Machada, A. de O., Rosa, F. S. da, \& Telles, J. (2011). Funções da Controladoria: um estudo nas 100 maiores empresas do Estado de Santa Catarina. Análise psicológica, 29(2), 345-361. http://www.scielo.mec.pt/pdf/aps/v29n2/v29n2all.pdf.

Lunkes, R. J., Schnorrenberger, D., \& Rosa, F. S. (2013). Funções da controladoria: uma análise no cenário Brasileiro. Revista Brasileira de Gestão de Negócios, 15(47), 283-289. https://doi.org/10.7819/rbgn.v15i47.1185.

Maroco, J., \& Garcia-Marques, T. (2006). Qual a fiabilidade do alfa de Cronbach? Questões antigas e soluções modernas? Laboratório de Psicologia, 4(1), 65-90. http://repositorio.ispa.pt/bitstream/10400.12/133/1/LP\%204\%281\%29\%20-\%2065-90.pdf.

McShane, S. L. (2014). Comportamento organizacional: conhecimento emergente, realidade global. Porto Alegre: McGraw Hill education.

Mosimann, C. P., \& Fisch, S. (1999). Controladoria: seu papel na administração de empresas. São Paulo: Atlas.

Nascimento, A. M., \& Reginato, L. (2010). Controladoria: instrumento de apoio ao processo decisório. São Paulo: Atlas.

Nunes, A. A. B., \& Sellitto, M. A. (2016). A Controladoria como suporte à estratégia da empresa: estudo multicaso de empresas de transporte. Revista de Administração Mackenzie, 17(1), 135-164. https://doi.org/10.1590/1678-69712016/administracao.vl7nlpl35-164.

Oliveira, L. M., Perez Junior, J. H., \& Silva, C. A. S. (2017). Controladoria estratégica. (11 ${ }^{a}$ ed.). São Paulo: Atlas.

Oro, I. M., Beuren, I. M., \& Carpes, A. M. da S. (2013). Competências e habilidades exigidas do controller e a proposição para sua formação acadêmica. Contabilidade Vista e Revista, 24(1), 15-36. https://revistas.face.ufmg.br/index.php/contabilidadevistaerevista/article/ view/593. 
Oro, I. M., Dittadi, J. R., Carpes, A. M. S., \& Benoit, A. D. (2009). O perfil do profissional de Controladoria sob a ótica do mercado de trabalho brasileiro. Pensar Contábil, 11(44), 5-15. http://www.atena.org.br/revista/ojs-2.2.3-06/index.php/pensarcontabil/article/viewFile/75/75.

Palomino, M. N., \& Frezatti, F. (2016). Role conflict, role ambiguity and job satisfaction: perceptions of the Brazilian controllers. Revista de Administração, 51(2), 165-181. https://doi. org/10.5700/rausp1232.

Peleias, I. R., Guimarães, P. C., Silva, D. da, \& Ornelas, M. M. G. de. (2008). Identificação do perfil profissiográfico do profissional de contabilidade requerido pelas empresas, em anúncios de emprego na região metropolitana de São Paulo. Revista de Administração e Contabilidade da Unisinos, 5(2), 131-141. https://www.redalyc.org/pdf/3372/337228635006. pdf.

Reginato, L., \& Nascimento, A. (2007). Um estudo de caso envolvendo business intelligence como instrumento de apoio a controladoria. Revista Contabilidade \& Finanças, 18, 69-83. https://doi.org/10.1590/S1519-70772007000300007.

Rengel, R., Monteiro, J. J., Lunkes, R. J., Lavarda, C. E. F., \& Schnorrenberger, D. (2020). Efeito das características dos gestores na participação orçamentária mediado pela percepção de justiça processual. Revista Contabilidade, Gestão e Governança, 18 (2), 256 275. http://dx.doi.org/10.21714/1984-3925_2020v23n2a7.

Ribeiro, L. M.S., Lunkes, R.J., Schnorrenberger, D., \& Gasparetto, V. (2008). Perfil do controller em empresas de médio e grande porte da grande Florianópolis. Revista Catarinense da Ciência Contábil, 20(7), 57-70. http://revista.crcsc.org.br/index.php/CRCSC/article/ view/1066.

Robbins, S. P. (2006). Comportamento organizacional. São Paulo: Pearson Prentice Hall.

Robbins, S. P. (2011). O processo administrativo: integrando teoria e prática. São Paulo: Atlas.

Roehl-Anderson, J. M., \& Bragg, S. M. (1996). Manual del controller: FUNCIONES, procedimientos y responsabilidades. Deusto: Barcelona.

Sá, E. G., \& Amorim, T. N. G. F. (2017). Principais competências exigidas aos profissionais da área de controladoria em empresas comerciais da região metropolitana de Recife. REU. NA, 22(2), 44-65. https://revistas.una.br/reuna/article/view/822.

Sadir, M., \& Lipp, M. N. (2009). As fontes de stress no trabalho. Revista de Psicologia da Imed, 1(1), 114-126. https://doi.org/10.18256/2175-5027/psico-imed.vlnlpll4-126.

Silva, M. Z., Ames, A. C., \& Giordani, M. S. (2020). Discriminação salarial de gênero e a percepção dos agentes: análise na profissão de 'controller'. Revista Catarinense da Ciência Contábil, 19(1), 1-18. https://doi.org/10.16930/2237-766220202908.

Simon, H. (1965). Comportamento administrativo. Rio de Janeiro: USAID. 
Siqueira, J. R. M. de, \& Soltelinho, W. (2001). O profissional de controladoria no mercado Brasileiro - do surgimento da profissão aos dias atuais. Revista Contabilidade \& Finanças, 12(27), 66-77. https://doi.org/10.1590/S1519-70772001000300005.

Souza, G. H. C., Wanderley, C. A., \& Horton, K. (2020). Perfis dos controllers: autonomia e envolvimento dos profissionais de controladoria. Advances in Scientific and Applied Accounting, 13(3), 3-22. https://doi.org/10.14392/asaa.2020130301.

Weick, K. (1979). The social psychology of organizing. Publisher: McGraw-Hil.

Zoni, L., \& Merchant, K.A. (2007). Controller involvement in management: an empirical study in large Italian corporations. Journal of Accounting \& Organizational Change, 3(1), 29-43. https://doi.org/10.1108/18325910710732849. 
